\title{
Remote Collaboration and Simulation Model for Weapons Development Based on Logistic
}

\author{
Li Suike*, Bai Sijun, Guo Yuntao and Wang Xubo
}

School of Management, Northwestern Polytechnical University, Xi'an, 710129, P.R. China

\begin{abstract}
The Logistic model and simulation algorithms in the ecological species were introduced to analyze the remote collaborative structure of weapons model development and the equilibrium and stability condition of its mode. The weapons development remote collaborative structure was designed, and two collaborative logistic models of the model development was built as "O-A" and "A-A". The stability conditions of two modes were calculated and policy implications were analyzed, dynamic evolution of the collaborative model was simulated by numerical simulation. Simulation results show that the stability of weapons development remote collaborative are closely related to research unit in collaboration with status, intrinsic growth rate, initial size and the maximum amount of output. The policy recommendations were given out for the weapons development units in remote collaboration with two types of collaborative mode under stable conditions.
\end{abstract}

Keywords: Logistic, remote collaboration model, simulation, weapon development.

\section{INTRODUCTION}

Weapons development requires the participation of many development units to remote collaboration and implementation, which spread across different geographical locations and different areas of expertise. In weapons development work in the remote collaboration process, there is a lot of information between various research units to interact, share, save, and modify, project constraints such as time, resources, costs and project tasks overlap, change, conflict and work together. Therefore, weapons development projects under the remote collaborative work environment have some features such as environmental uncertainty, factors affecting organization and management complexities [1].

Remote collaboration is the foundation of weapons development, which already has a larger proportion of practical and theoretical studies at home and abroad, mainly in remote collaborative design and project management system for remote collaboration. Remote collaborative design process emphasizes the subject, synergy, commons, and flexibility, and combines multiple companies or departments to jointly design through the remote computer network [2, 3]. Through the use of computers, project management, Internet-related technology, the remote collaborative project management system proposes the remote collaborative project management methods, models and tools, such as: Mikko Uoti introduced the concept of collaborative projects [4]. Z. Ren came up with a e-HUBs (eEngineering enabled by Homonymic and Universal Broker Services) to develop remote collaborative project planning methods [5]. Fatma Cemile Serce researched a global software development team collaboration models and patterns of behavior [6]. Gao Weina proposed collaborative project management and collaborative project management system framework [7]. Jia Xiaoliang proposed project concurrent and collaborative digital platform based on 3DPLM (Product Lifecycle Management) [8]. Current research focused on remote collaboration technologies, methodologies and frameworks, ignored the known limitations of synergy principal and competitive interactions between the cooperative units, and less involved weapons development stability of remote collaboration system.

Remote collaborative stability is a key issue that relates to the living basis for weapons equipment product development system [9]. With the progress of scientific research, scholars have found that the competitive interaction between organizations has characteristics similar to the competition between species. By the principle of bionics, from the ecological point of view to study the relationship between the organization and interactive strategy becomes a new perspective [10]. This paper described the logistic model of population phenomena in biology; researched on weapons development remote collaboration system entities and their relationships, analyzed stability conditions for weapons development remote collaboration, and simulated using MATLAB to study on the dynamic evolution of remote collaboration.

\section{REMOTE COLLABORATIVE STRUCTURES FOR} WEAPONS DEVELOPMENT AND ANALYSIS

\subsection{Remote Collaboration Structure of Weapons Development}

According to the profession or nature, weapon equipment development project is divided into several sub-projects 
$\left(\mathrm{P}=\left\{\mathrm{P}_{1}, \mathrm{P}_{2}, \mathrm{P}_{3}, \ldots\right\}\right)$. Based on the support platform of remote collaboration system, each research unit $\left(A_{1}, A_{2}, A_{3}\right.$, ...) combines with the master research unit (O) to complete project tasks $\left(\mathrm{Pi}=\left\{\mathrm{T}_{\mathrm{i} 1}, \mathrm{~T}_{\mathrm{i} 2}, \mathrm{~T}_{\mathrm{i} 3}, \ldots\right\}\right)$ by division of labor and collaboration in the weapons development industrial systems.

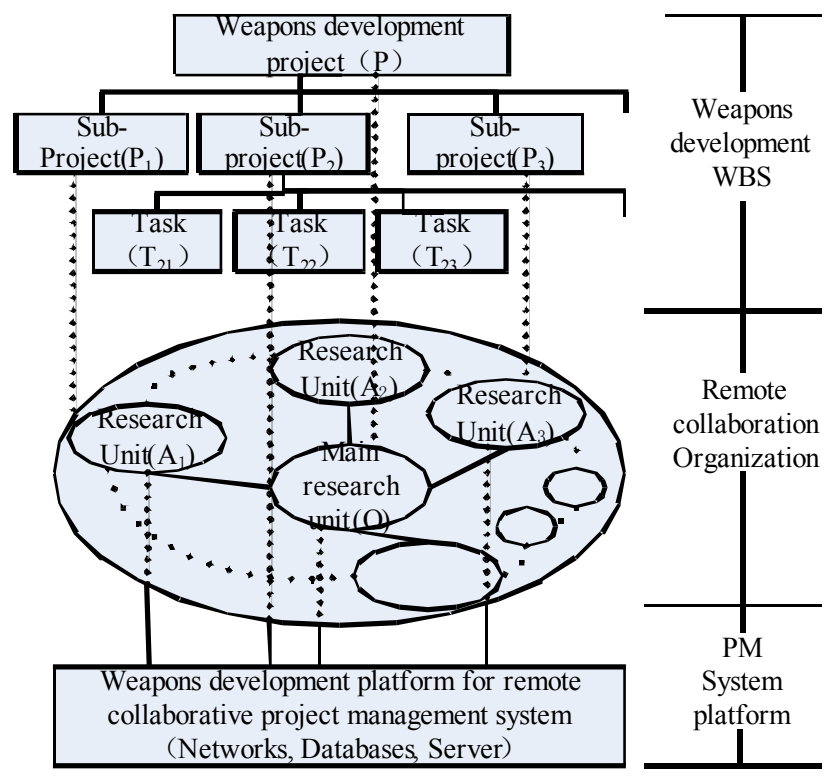

Fig. (1). Weapons development remote collaborative structure.

As shown in Fig. (1), the main research unit with core competitive power bears the main tasks for weapons development and remote collaborative organizational mandates, and is at the heart of industrial clusters in weapons development. Relying on its own strength and expertise, numerous research and development units shall bear their own tasks and are at synergy. For a shorter development cycle of the weapon to ensure the timeliness of weapons and equipment, many development tasks must be carried out in parallel and close collaboration between the various research units is required. In the remote collaboration system for weapons development, there are primarily two modes: (1) main research units are as the core and research unit cooperates as "O-A" cooperative mode; (2) by virtue of their special skills, various research units take collaboration and interaction as "A-A "cooperative mode.

\subsection{Logistic Implications and Assumptions}

In biology, the logistic model was used to describe the evolution (growth law) of the number of the species in a limited environment, and sometimes was used to depict interactions between species. In nature, population growth, the spread of disease and the promotion of technological innovations are to meet the growth law of logistic model [11].

Assuming the existence of enterprises cluster environment changes over time, interaction causes changes in output among research units as well as with the external environment in remote collaboration weapons industry cluster. For computing simple and intuitive expression, makes the following assumptions: (1) enterprise's output is a function of time $\mathrm{t}$, expressed as $\mathrm{x}(\mathrm{t})$; (2) in limited environments, corporate yields a maximum value, expressed as $\mathrm{N}$; (3) saturation for the natural growth of enterprises in t, expressed as, which blocks effect of output growth for enterprises, expressed as (1- ); (4) own industry's average growth rate (intrinsic rate) associated with the immobilization of the industry itself, represented as $r$. In the State of nature, evolution of enterprise output can be described as:

$x(t+1)=r x(t)\left(1-\frac{x(t)}{N}\right)$

This paper used Logistic model to describe the remote collaborative weapons development. In the model, changes experienced by the research units were reduced to the level of output. Stability condition and evolution of two remote collaboration modes were described through changes in output levels.

\section{REMOTE COLLABORATION MODEL BASED ON LOGISTIC AND STABILITY CONDITIONS}

\section{1. "O-A" Remote Cooperative Mode}

\subsubsection{Establishment of the Model}

Assume that $\mathrm{O}$ (primary research unit) can stand alone, the level of $\mathrm{O}$ output growth in accordance with the law of Logistic growth. A (research unit) provides professional support, resources and technologies to increase the $\mathrm{O}$ output capacity. Therefore, the growth law of $\mathrm{O}$ output level is described as:

$x_{1}(t+1)=r_{1} x_{1}(t)\left(1-\frac{x_{1}(t)}{N_{1}}+s_{1}^{\prime} \frac{x_{2}(t)}{N_{2}}\right)$

As in (2) , $r_{1}$ is the intrinsic growth rate of output level of $x_{1}(t), N_{1}, N_{2}$. are respectively the maximum amount of output $\mathrm{O}, \mathrm{A}$. And $s_{1}^{\prime}$ expresses the level of contribution of $\mathrm{A}$ natural increase saturation to output growth level of $\mathrm{O}, s_{1}^{\prime}>0$. In the "O-A" remote collaboration system, the research units are attached to the main research units. Disappearence of $\mathrm{O}$ will also bring demise to $\mathrm{A}$, assume that its mortality rate is $r_{2}^{\prime}$, and that can be described as:

$x_{2}(t+1)=-r_{2}^{\prime} x_{2}(t)$

At the same time, $\mathrm{O}$ provide development tasks and output needs to A, which means the expansion of the market. And assume that $S_{2}$ expresses the level of contribution of $\mathrm{O}$ natural increase saturation to output growth level of A. Level of output growth promotion effect $\mathrm{O}$ to $\mathrm{A}$ should be added to the right side of (3), it is:

$x_{2}(t+1)=r_{2}^{\prime} x_{2}(t)\left(-1+s_{2} \frac{x_{1}(t)}{N_{1}}\right)$

Meanwhile the output growth level of A is blocked because of its growth, and the right side of (4) should also add the Logistic, the equation becomes: 
$x_{2}(t+1)=r_{2}^{\prime} x_{2}(t)\left(-1+s_{2} \frac{x_{1}}{N_{1}}-\frac{x_{2}}{N_{2}}\right)$

Married equation (2) and (5), weapons development "OA" remote collaboration model is drawn to:

$\left\{\begin{array}{l}x_{1}(t+1)=r_{1} x_{1}(t)\left(1-\frac{x_{1}(t)}{N_{1}}+s_{1}^{\prime} \frac{x_{2}(t)}{N_{2}}\right) \\ x_{2}(t+1)=r_{2}^{\prime} x_{2}(t)\left(-1+s_{2} \frac{x_{1}}{N_{1}}-\frac{x_{2}}{N_{2}}\right)\end{array}\right.$

\subsubsection{Stability Analysis}

Through the transformation equations (6) and analysis of the equilibrium point stability, changes in output levels of two subject after a long enough time discussion are as shown in Table $\mathbf{1}$.

Table 1. "O-A" remote cooperative model balance and stability.

\begin{tabular}{|c|c|}
\hline Balance Point & Stable Conditions \\
\hline \hline$p_{1}\left(N_{1}, 0\right)$ & $s_{2}<1, s_{1}^{\prime} s_{2}<1$ \\
\hline$p_{2}\left(\frac{N_{1}\left(1-s_{1}^{\prime}\right)}{1-s_{1}^{\prime} s_{2}}, \frac{N_{2}\left(s_{2}-1\right)}{1-s_{1}^{\prime} s_{2}}\right)$ & $s_{1}^{\prime}<1, s_{2}>1, s_{1}^{\prime} s_{2}<1$ \\
\hline$p_{3}(0,0)$ & Instability \\
\hline
\end{tabular}

\section{2. "A-A" Remote Cooperative Mode}

\subsubsection{Establishment of the Model}

Assume that both model research units $A_{1}$ and $A_{2}$ have independent existence on weapons development in industrial clusters, and the evolution of their output levels comply with the Logistic law when they live alone in the organizational environment. Weapons development in remote collaboration system, $A_{1}$ and $A_{2}$ synergies in close cooperation and between all of them is to promote and raise the level of output. $x_{1}(t), x_{2}(t)$ are respectively the research output of the $\mathrm{A}_{1}, \mathrm{~A}_{2}, r_{1}$ and $r_{2}$ are respectively the intrinsic growth rate of output level of $x_{1}(t)$ and $x_{2}(t), N_{1}, N_{2}$ are respectively the maximum amount of output $A_{1}, A_{2}$.

Weapons development "A-A" remote collaboration model is built as shown in the following:

$$
\left\{\begin{array}{l}
f\left(x_{1}, x_{2}\right)=r_{1} x_{1}\left(1-\frac{x_{1}}{N_{1}}+s_{1} \frac{x_{2}}{N_{2}}\right) \\
g\left(x_{1}, x_{2}\right)=r_{2} x_{2}\left(1+s_{2} \frac{x_{1}}{N_{1}}-\frac{x_{2}}{N_{2}}\right)
\end{array}\right.
$$

\subsubsection{Stability Analysis}

Through the transformation equations (7) and analysis of the equilibrium point stability, 4 balance points were received. According to judge the stability method of the equilibrium point, stable conditions are as shown in Table 2.
Table 2. "A-A" remote cooperative model balance and stability.

\begin{tabular}{|c|c|}
\hline Balance Point & Stable Conditions \\
\hline \hline$p_{1}\left(N_{1}, 0\right)$ & $s_{1}<1, s_{2}>1$ \\
\hline$p_{2}\left(0, N_{2}\right)$ & $s_{1}>1, s_{2}<1$ \\
\hline$p_{3}\left(\frac{N_{1}\left(1+s_{1}\right)}{1-s_{1} s_{2}}, \frac{N_{2}\left(1+s_{2}\right)}{1-s_{1} s_{2}}\right)$ & $s_{1}<1, s_{2}<1$ \\
\hline$p_{4}(0,0)$ & Instability \\
\hline
\end{tabular}

\section{NUMERICAL SIMULATION AND ANALYSIS}

\subsection{Simulation and Analysis of "O-A" Remote Collaboration Model}

According to the above criteria, assume respectively that $x_{1}(t)=0.1, x_{2}(t)=0.1, r_{1}=2.5, r_{2}^{\prime}=1.8, N_{1}=1.6, N_{2}=1$, and assign values respectively to $s_{1}^{\prime}, s_{2}$ based on the $P_{1}, P_{2}$. Carry out simulation of changing trends of remote collaboration output levels associated with time used by MATLAB, as shown in the following figure.

Through the research of Fig. (2), equations are derived from the stability criteria: unstable equilibrium point is $p_{2}, \mathrm{O}$ and A can stable remote collaboration with each other. (1) Conditions of stable balance points: $\mathrm{s}_{1}{ }^{\prime}<1, \mathrm{~s}_{2}>1, \mathrm{~s}_{1}{ }^{\prime} \mathrm{s}_{2}<1$. That is, no matter what the circumstance, if the grinding unit contribute little to the output level of main research unit (that is, $\left.\mathrm{s}_{1}{ }^{\prime}<1\right)$, and the main research unit enhances a large contribution to output levels of grinding unit $\left(s_{2}>1\right)$, while meeting $\mathrm{s}_{1}$ ' $\mathrm{s}_{2}<1$ (requires $\mathrm{s} 1$ ' is small and $\mathrm{s} 2$ is larger), they will be able to achieve stability of the cooperative equilibrium. (2) In the equilibrium stability condition, output level for main research units is: $N_{1}\left(1-s_{1}^{\prime}\right) /\left(1-s_{1}^{\prime} s_{2}\right)>$ $N_{1}$. That is, in case some research units for remote collaboration, main research unit are output level is greater than its individual development level of output. After the development of remote collaborative weapons development, main research unit could be more professional in their expertise, to develop its own core products and improve their competitiveness, through the outsourcing and remote collaboration of development.

\subsection{Simulation and Analysis of "A-A" Remote Collaboration Model}

According to the above criteria, assume respectively that $x_{1}(t)=0.1, x_{2}(t)=0.1, r_{1}=2.5, r_{2}=1.8, N_{1}=1.6, N_{2}=1$, and assign values respectively to $s_{1}, s_{2}$ based on the $P_{1}, P_{2}, P_{3}$. Carry out simulation of changing trends of remote collaboration output levels associated with time used by MATLAB, as shown in the following figure:

Through the comparative analysis of Figs. (1-3), the stable equilibrium is $P_{3}$, in this case members of the 


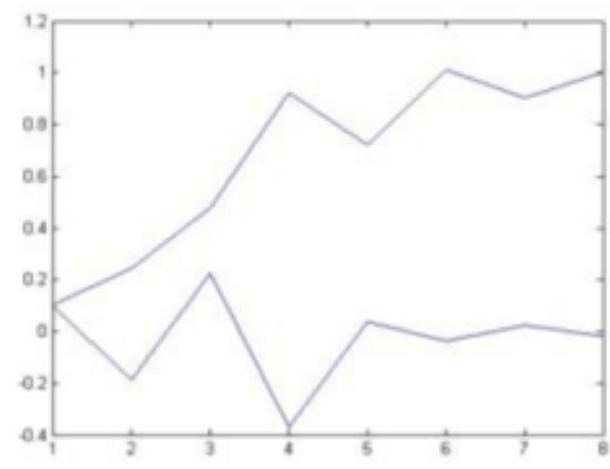

$(2-1)^{s_{1}^{\prime}}=0.3, s_{2}=0.9$

Fig. (2). Simulation of "O-A" remote collaboration model.

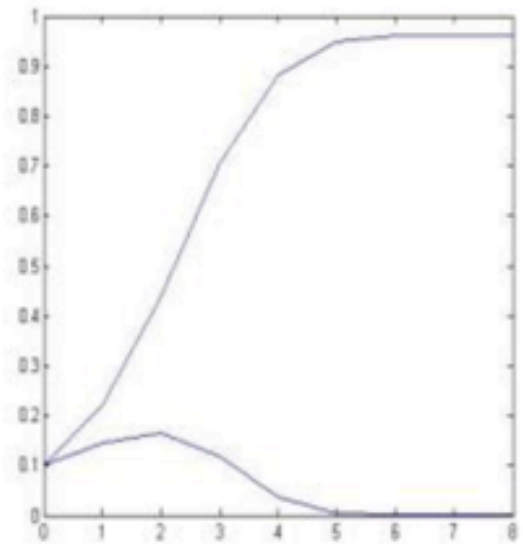

(3-1) $s_{1}=0.5, s_{2}=1.6$

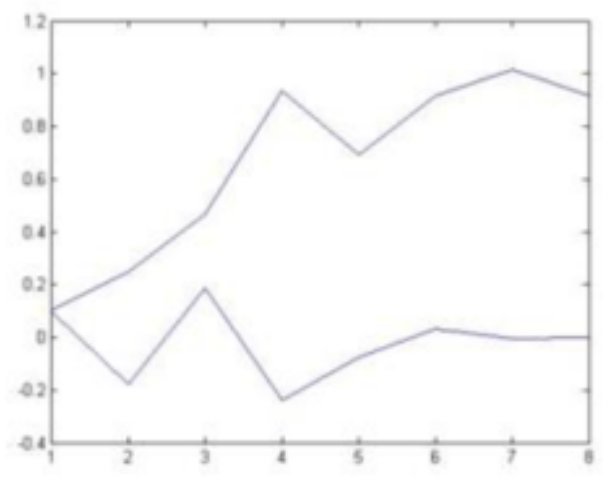

$(2-2) s_{1}^{\prime}=0.5, s_{2}=1.6$
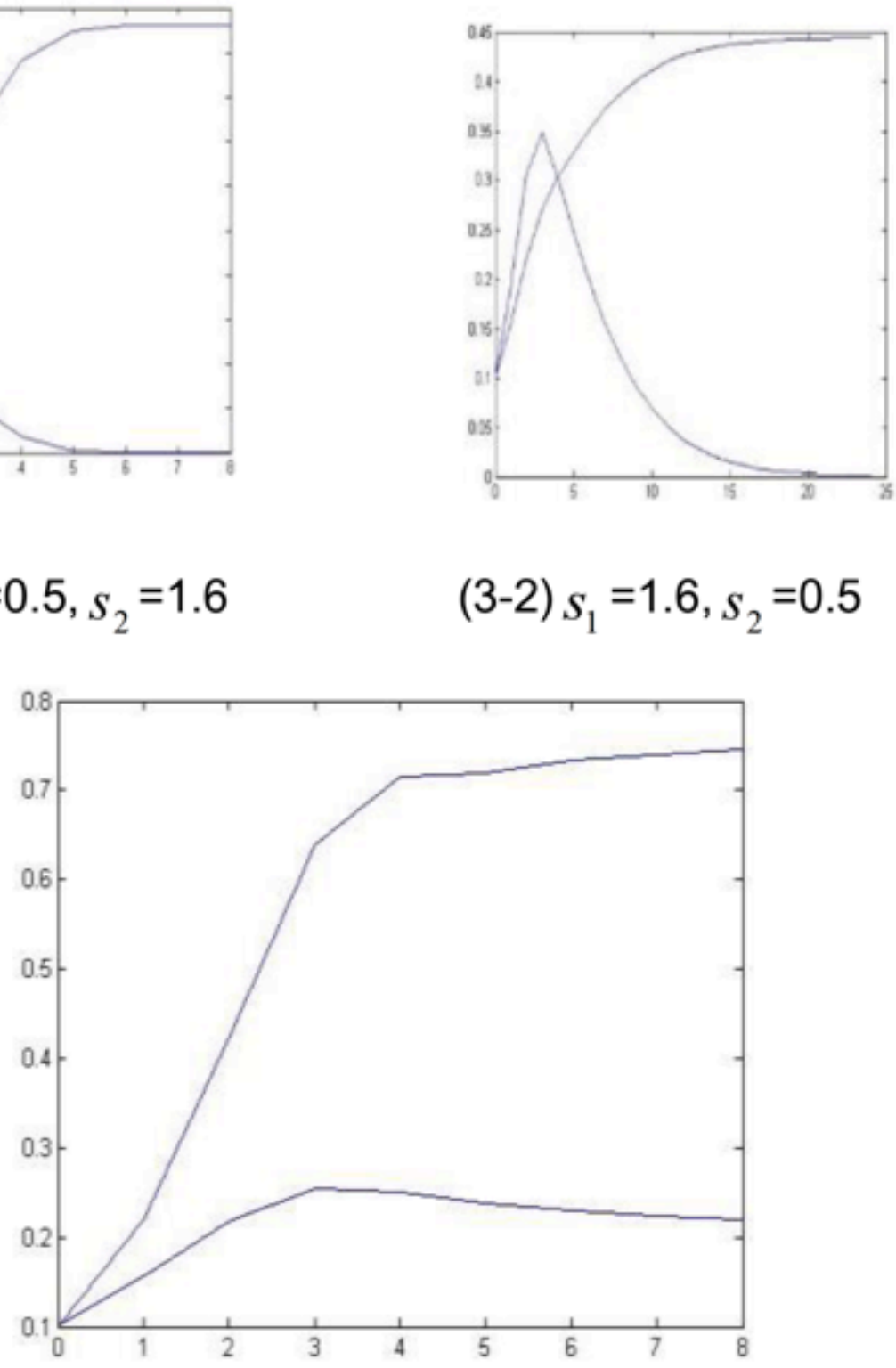

(3-3) $s_{1}=0.6, s_{2}=0.5$

Fig. (3). Simulation of "A-A" remote collaboration model. 
organization will coexist for remote collaboration and both $\mathrm{A}_{1}$ and $A_{2}$ can stable work together. (1) Stable equilibrium conditions: $0<\mathrm{s}_{1}<1,0<\mathrm{s}_{2}<1$. That is, research units $\left(\mathrm{A}_{1}\right.$ and $\left.\mathrm{A}_{2}\right)$ contributes relatively little to each other, research unit output levels contribute to each other mainly through collaboration, sharing of technical and management information about the imitation, and so on, arising from the division of labor. In order to maintain the stable conditions, there is competition between each other. (2) In the state of balance and stability, research unit level of output is $\mathrm{N}_{1}\left(1+\mathrm{s}_{1}\right) /\left(1-\mathrm{s}_{1} s_{2}\right)$, its factor of output level is $\left(1+\mathrm{s}_{1}\right) /\left(1-\mathrm{s}_{1} s_{2}\right)$, and will grow rapidly as the increase of $s_{1}, s_{2}$. That is, the output level of research unit is greater than its own independent research in the state of balance and stability. At the same time, output level of developed unit is growing rapidly with increasing saturation contribution offset natural growth in this environment of working closely with remote collaborative work.

\section{CONCLUSION}

By means of numerical simulation and stability analysis for weapons development remote collaboration mode, the objective facts of instability risk that exist in remote collaboration are revealed, and different stability conditions for remote collaborative mode are distinguished, in order to support decision making for weapons development remote collaboration.

(1) In the case of "O-A" remote collaboration mode, there needs the following three essentials for balancing steady state: (1) Research unit resource flows accounted for limited proportion of the total amount of input or output of the main research unit, in order to avoid monopoly; (2) input or output resource flows of the main research unit must account for a large proportion of research units total flow; (3) there requires that the main research unit model development tasks are more or distribution of research units are wider, while resources flows of the main research units are greater to ensure limited competition between research units. So, the main research units should focus on enhancing the institute's industry type, number of units and associated biodiversity, to ensure that when there is a problem in the unit of nexus research cooperative the new collaborative space will be filled with new research units or new collaborative industry chain will be built, to increase the overall ability to counter risks of the weapons development for remote collaboration.

(2) In the case of "A-A" the collaborative mode, the steady symbiotic conditions are that contribution of research unit to each other is not too big, and it indicates that remote collaboration between research units to improve overall benefits of collaborative space is limited. Therefore, research units should be fully exploiting resources within organization, extend and expand remote collaborative development chain, widely be associated with other enterprises of the same trade, industry, upstream and downstream industries develop mutually beneficial cooperative relations, so as to expand the ways of increasing the benefits for remote weapons development collaborative.

\section{CONFLICT OF INTEREST}

The authors confirm that this article content has no conflict of interest.

\section{ACKNOWLEDGEMENTS}

This study was sponsored by National Natural Science Foundation of China (No. 71172123), Aviation Science Fund (NO. 2012ZG53083), Soft Science Foundation of Shaanxi Province (No. 2012KRM85) and the funds of NPU for Humanities \& Social Sciences and Management Revitalization (No. RW201105).

\section{REFERENCES}

[1] G. Yuntao, B. Sijun, and C. Xingzhong, "Collaborative work-oriented model of airborne weapon equipment development project management structure", Chinese Journal of Management, vol. 19, pp. 31-33, 2005.

[2] L. Zhihua, L. Chunwei, et al. "Research and implementation on distributed synchronous cooperative design techniques", The electrical and mechanical services, vol. 24, pp. 17-19, February 2007.

[3] L. Wang, W. Shen, H. Xie, J. Neelamkavil, and Ajit Pardasani, "Collaborative conceptual design-state of the art and future trends", Computer-Aided Design, vol. 34, pp.981-996, 2002.

[4] M. Uoti, K. Jansson, I. Karvonen, M. Ollus, S. Gusmeroli, "A configurable model and tool for managing critical shared processes in collaborative projects" Helsinki: IEEE Computer Society, pp. 87-96, 2011.

[5] Z. Ren, C.J. Anumba, T.M. Hassan, G. Augenbroe, and M. Mangini "Collaborative project planning: A case study of seismic risk analysis using an e-engineering hub," Computers in Industry, vol. 55, pp. 218230, 2006.

[6] F. C. Serce, K. Swigger, F. N. Alpaslan, R. Brazileb, G. Dafoulasd, and V. Lopez, "Online collaboration: Collaborative behavior patterns and factors affecting globally distributed team performance," Computers in Human Behavior, vol. 27, pp. 490-503, 2011.

[7] G. Weina, X. Liang, et al. "Network business-oriented collaborative project management information system", Manufacturing Automation, vol. 25, pp. 37-40, December 2003.

[8] J. Xiaoliang, "Life cycle quality management technology of aviation complex product based on 3D-PLM collaborative", Aeronautical Manufacturing Technology, pp. 76-80, December 2011.

[9] W. Xiaobing, G. Yuntao, and B. Sijun, "Reasons and countermeasures analysis of aviation weapon equipment project," Chinese Journal of Management, vol. 19, pp. 160- 162, 2005.

[10] F. Haizhou, and M. Hongmei, "Competitive interaction analysis of enterprise based on Logistic model", Industrial Engineering, vol. 13, pp. 39-42, March 2010.

[11] G. Li, and S. Jingqin, "Stability analysis of industrial symbiosis based on Logistic growth model", Forecast, vol. 24, pp. 25-29, January 2005.

This is an open access article licensed under the terms of the Creative Commons Attribution Non-Commercial License (http://creativecommons.org/licenses/ by-nc/3.0/) which permits unrestricted, non-commercial use, distribution and reproduction in any medium, provided the work is properly cited. 